\title{
Enhanced Paracetamol Oxidation and Its Determination using Electrochemically Activated Glassy Carbon Electrode
}

\author{
Mohamed I. Awad ${ }^{1,2, *}$, Ali Sayqal ${ }^{1}$, Rami Adel Pashameah ${ }^{1}$, Ahmed M. Hameed ${ }^{1}$, Moataz Morad ${ }^{1}$, \\ Hussain Alessa ${ }^{1}$, Reem Kamal Shah ${ }^{1}$, Mohammed. A. Kassem ${ }^{1,2, *}$ \\ ${ }^{1}$ Chemistry Department, Faculty of Applied Science, Umm Al-Qura University, Makkah, Saudi \\ Arabia. \\ ${ }^{2}$ Chemistry Department, Faculty of Science, Cairo University, Cairo, Egypt \\ ${ }^{3}$ Chemistry Department, Faculty of Science, Benha University, Benha13518, Egypt

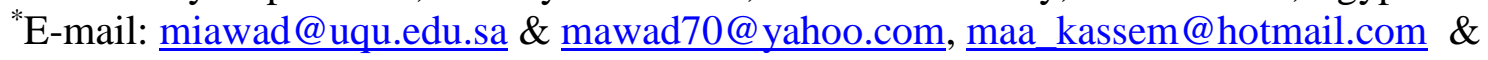 \\ makassem@uqu.edu.sa
}

doi: $10.20964 / 2021.01 .12$

Received: 25 August 2020 / Accepted: 11 October 2020 / Published: 30 November 2020

\begin{abstract}
Herein, the impact of electroactivation of glassy carbon electrode on the paracetamol drug electrochemical behavior is investigated for the first time. The morphology of the GC electrode surface was investigated using SEM. The extent of oxidation of GC as well as the $\mathrm{pH}$ of the supporting electrolyte has been investigated. The oxidation of GC results in the formation of several containing oxygen functional groups which increases with increasing the number of potential cycles for oxidation. The extent of GC oxidation was quantified by calculating the number of surface's quinone units (S), as calculated from the voltammetric measurements in $1.0 \mathrm{M} \mathrm{H}_{2} \mathrm{SO}_{4}$. Then the $\mathrm{S}$ was correlated with the extent of electrocatalytic oxidation of PC. Based on the voltammetric studies, it has been found that the oxidation of PC is controlled by both diffusion and adsorption processes. Finally, the activation of GC electrode was used for the quantitative determination of PC in a suitable rectilinear range with a standard devation and relataive standard deviation (RSD) of $0.17 \mathrm{mM}$ and $2.4 \%$, respictively.
\end{abstract}

Keywords: Oxidized glassy carbon; Paracetamol; Cyclic voltammetry; Electrocatalysis; Analytical determination.

\section{$\underline{\text { FULL TEXT }}$}

(C) 2021 The Authors. Published by ESG (www.electrochemsci.org). This article is an open access article distributed under the terms and conditions of the Creative Commons Attribution license (http://creativecommons.org/licenses/by/4.0/). 